\title{
Knowing and Understanding how to Manage One's Physical Activity Practice: Contribution of Language, Thinking and Intelligence to Physical Literacy
}

\author{
By Paul Godbout *
}

\begin{abstract}
Agreed upon components of physical literacy are (a) physical competence, (b) knowledge and understanding, (c) motivation and confidence, and (d) lifetime engagement. The purpose of this article is to discuss the development and use of the "knowledge and understanding" PL component in older students and adults with regard to the regulation of their health/fitness- and leisure-related physical-activity-practice (PAP). In a first section the author considers the pedagogical content knowledge (PCK) and the basic language that may be associated with the management of health- and fitness-oriented physical activities, differentiating elements that pertain to declarative, procedural or conditional knowledge. Based on exercise-monitoring procedures (E-MP) (essentially procedural knowledge) and on exercise-management rules (E-MR) (mostly conditional knowledge), the following section focuses on the development of PAP-management understanding and the related intelligence in its analytical, creative and practical dimensions. In a final section, the author explores briefly the matter of awareness and regulation in terms of exercise-management knowledge and understanding.
\end{abstract}

Keywords: exercise-management awareness, exercise-management regulation, FITT formula, physical-activity monitoring

\section{Introduction}

According to Whitehead (2013, p. 29) "physical literacy can be described as a disposition to capitalize on our human embodied capability, wherein the individual has: the motivation, confidence, physical competence, knowledge and understanding to value and take responsibility for maintaining purposeful physical pursuits/activities throughout the life course." Knowledge and understanding are two constructs regularly discussed in sport pedagogy, particularly in relations with the teaching/learning of team sports. In the above Whitehead's (2013) definition of physical literacy (PL), the two constructs encompass a much broader meaning. Among six attributes associated with making progress on one's individual/unique physical-literacy journey with intelligence and imagination, no less than four may be associated one way or the other with "knowledge and understanding" (Whitehead 2013, pp. 29-30, bold characters added by the author):

(1) Sensitive perception in 'reading' all aspects of the physical environment, anticipating movement needs or possibilities and responding appropriately to these, with intelligence and imagination.

"Professor Emeritus, Laval University, Canada. 
(2) A well-established sense of self as embodied in the world. This together with an articulate interaction with the environment, engenders positive self-esteem and self-confidence.

(3) Sensitivity to and awareness of embodied capability, leading to fluent self-expression through non-verbal communication and to perceptive and empathetic interaction with others.

(4) The ability to identify and articulate the essential qualities that influence the effectiveness of movement performance, and an understanding of the principles of embodied health, with respect to fundamental aspects such as exercise, sleep and nutrition.

Considering Whitehead's (2013) definition, the ultimate manifestation of PL is for an individual to maintain purposeful physical pursuits/activities throughout his/her life course. Taken literally, such a statement would imply an overwhelming amount of knowledge and understanding if it were to encompass utilitarian and non-utilitarian physical activities, regardless of their purpose and energy requirements. Going through Whitehead's (2013, p. 31) definition of physical illiteracy, one can work out the extent of PL as conceived by this author. In so doing, she appears to be describing a state of mind, a way of being, one way or the other. "Physically illiterate individuals will avoid any involvement in physical activity in all situations wherever alternatives are possible. This could include not walking short distances, avoiding tasks such as house cleaning and gardening, ... Individuals will not be motivated to take part in structured physical activity ..."

At the opposite, PL would encompass all participation in physical activity throughout the life course, being as valuable to the average performer and those with particular challenges to overcome, as it is to the most able. Coming back to the above mentioned ultimate manifestation of PL, the phrase "for an individual to maintain purposeful physical pursuits/activities" bears a strong significance: it is accepted from the start, or as a premise, that physical-activity (PA) literates exercise on purpose, hence the complexity of determining which knowledge and understanding are at stake. Performing physical activities in view of physical health and fitness, leisure, work chores, high performance, family chores, improving one's physical appearance, mental health, etc., or a combination of these are all plausible reasons for becoming or remaining physically active. Motives vary and may be basically intrinsic, somewhat extrinsic or internalized to various extents (Ryan and Deci 2020). Driven by different motives, PA literates may thus need to rely on diverse types of knowledge and possibly different levels of understanding.

Whatever particular field of knowledge is concerned with regards to physical activity, individuals need to grasp at least the basic terminology if they are to function with a reasonable level of autonomy (Wickens and Parker 2019). For example, in the context of tactical learning in team sports with a socioconstructivist approach, Godbout and Gréhaigne (2021) have discussed the development of game-play language and game-play intelligence, using knowledge and understanding as a background reference. The semantic process and constructs involved in solving PA-related challenges remains basically the same whatever the 
activities concerned and despite the specifics of a particular PA area. Throughout their schooling, individuals are exposed to curriculum-content elements that cover PAs such as fundamental skills, sports, dance and creative movement, and fitness activities. Having developed an interest for particular communities of practice, older students (high school and college levels) may also wish to explore other activities related either to dance education, outdoor education, sport education (see Author's note 1 at the end of the article), or other recreation programs. Such a vast array of physical activities represents a considerable amount of content knowledge, way beyond the scope of an article. However, all these activities have in common the fact that they have an impact on the human body. A few years after reaching adulthood, individuals become gradually confronted with the emergence of a slow decline in terms of general physical fitness (Bonnie et al. 2015, Lumen learning team 2019). Unless they are prepared to face and react to these bodily changes, they may find it difficult to remain or become PA literate. In a study conducted with 291 middle-school students, Zhang et al. (2020) concluded that "[students'] incapability to engage in fitness-enhancing physical activities could be a result of lacking procedural fitness knowledge. Future school-based interventions may prioritize procedural knowledge learning for actual physical activity participation".

The purpose of this article is to discuss the development and use of the "knowledge and understanding" PL component in older students and adults with regard to the regulation of their health/fitness- and leisure-related physical-activitypractice (PAP) management. In a first section, the author considers the pedagogical content knowledge (PCK) and the basic language that may be associated with the management of health- and fitness-oriented physical activities, differentiating elements that pertain to declarative, procedural or conditional knowledge. Based on exercise-monitoring procedures (E-MP) (essentially procedural knowledge) and on exercise-management rules (E-MR) (mostly conditional knowledge), the following section focuses on the development of PAP-management understanding and the related intelligence in its analytical, creative and practical dimensions. In a final section, the author explores briefly the matter of awareness and regulation in terms of exercise-management knowledge and understanding.

\section{Knowledge and Language with Regard to Health- and Fitness-Oriented Physical Activities}

The distinction between declarative, procedural and conditional knowledge has become a classic in terms of knowledge-level categories (Schunk 2012). For instance, naming the components of the FITT formula (Frequency, Intensity, Time, Type; see Godbout and Nadeau 2021), an essentially recall exercise, would concern a piece of declarative knowledge. Any piece of information retrieved from memory belongs to the realm of declarative knowledge. Knowing how to measure one's heart rate would be representative of a piece of procedural knowledge: given a specific task or situation, this is how one should proceed. Knowing why and when implement a given procedure (e.g., increase the intensity or length of a bout 
of exercise) is representative of conditional knowledge; it implies a higher level of understanding on the part of the performer. At each of these three levels of knowledge, understanding is at play. However, as we go from declarative to conditional knowledge, the complexity of mental processes, encompassed under the "understanding" label, increases.

There has been in the last quarter of a century an increasing interest for competence-based education (Klieme et al. 2008, Wesselink et al. 2010), starting with vocational education and training. The competence construct may be seen as a "context-specific cognitive disposition that is acquired by learning and is needed to successfully cope with certain situations or tasks in specific domains" (Klieme et al. 2008, p. 9). A relationship with the three categories of knowledge defined above is implicitly suggested by Escalié et al. (2019, p. 391) when they write "competence can be understood as an integrated and stable network of knowledge and know-how comprising normative behaviors, procedures and types of reasoning that students can use to manage complex situations". The notion of competence has also been used in Physical Education (e.g., Weiss 2011) and Health Education (e.g., Sudeck and Pfeifer 2016). In this article, in order to stay aligned with the "knowledge and understanding" PL component, the author will refer to diverse categories of knowledge as underlying support for PAP management competences.

Development and use of knowledge and understanding in any sphere of human experience require perception of one's reality and resorting to mental processes to assimilate or accommodate it. In that respect, fundamental capacities to be considered are language and intelligence; this last construct will be discussed later.

As is the case in sport activities, learning about the regular use of other physical activities in view of developing or maintaining one's physical fitness requires a certain mastery level of the related language. With regards to tactical learning in team sports, Godbout and Gréhaigne (2021, p. 53) wrote "during their debates or exchanges, learners resort back and forth to their everyday language, for general comments, and to game-play language for exchanges concerning subjectmatter elements or tactical and strategic aspects of game-play". Accessing or providing relevant information about the management of PAP implies reading, exchanging or debating and thus, recalling and understanding the terminology associated with health-and-fitness content knowledge and its related pedagogical content knowledge (PCK) (Amade-Escot 2000).

\section{Health and Fitness Pedagogical Content Knowledge}

Considering the actual practice of PAs in view of developing and maintaining one's physical fitness (PF) directly involves two of the four PL components, physical competence and lifetime engagement. Thus, health- and fitness-related PCK may in a sense be associated with two dimensions of PA: (a) knowledge about motor and tactical skills specific to any PA likely to contribute to PF; and (b) knowledge about the proper management of the activity so that it may effectively have an impact on one's PF level. In this article, the author takes it for granted that 
older students (senior high school and college level) and adults have developed, throughout their childhood and adolescence, a certain amount of motor and tactical skills either related to sports, dance and creative movement, muscular exercise skills, and/or outdoor activities, etc. Their experiences may have been restricted to PE classes or may have also have been associated with dance education, outdoor education, sport education, or other recreation programs on a community basis or a private one. The potential content knowledge and related PCK associated with such a large spectrum of activity is huge and beyond the scope of this article.

PCK targeted in the article relates to the way individuals may take advantage of one or many PAs to develop and/or maintain their PF through a lifetime engagement. This kind of knowledge does not focus on motor skills, nor on tactical skills in their usual sense. It rather focuses on the use and management of such skills, given the way one's body reacts to PA (Cale and Harris 2018, Edwards et al. 2017, Konukman et al. 2010). As the reader will see later, tactical decisions may be involved but in a different way. First and foremost, notwithstanding interactions with other people, exercise involves one's body functioning in a physical environment. Performing a physical activity produces acute effects on the body due to an increase of the metabolism involving different systems. Performing physical activity on a regular basis will also produce chronic effects on the long run. Management of one bout of exercise calls for knowledge concerning acute effects. Management of a prolonged series of exercise sessions calls for knowledge concerning chronic effects over time (several weeks, one season, one year for instance). While chronic effects usually relate to goal pursued, health benefits and potentially ill effects, acute effects reflect stimuli applied to our body along with related adjustments to bodily functions.

\section{Health and Fitness Terminology}

Table 1 presents in a nutshell a series of words or expressions related to PAP; although not exhaustive, it covers a spectrum fairly representative of the language used by people who exercise on a regular basis. The semantic map of fitness words suggested by Konukman et al. (2010) is a good example of such an exercise. This terminology, essentially declarative knowledge, refers to concepts (physical objects or phenomena) and constructs (creations of the mind) that older students and adults are expected to master and understand if they are to manage their PAP. In a way, this terminology represents a part of the PL language concerned with "maintaining purposeful physical pursuits/activities". Whenever individuals wish or need to debate, exchange about their PAP or read about it, mastering this terminology remains an essential requirement. Although technically declarative, part of this knowledge is, for many physically active individuals, an embodied or experiential kind of knowledge in the sense that they have an intimate acquaintance with these realities. 
Table 1. Terminology Related to Physical Activity Practice

\begin{tabular}{|c|c|}
\hline $\begin{array}{l}\text { Body systems/Environment } \\
\text { terminology }\end{array}$ & $\begin{array}{l}\text { Related-concepts/constructs terminology } \\
\text { (Words in bold characters are safety- or injury-related) }\end{array}$ \\
\hline $\begin{array}{l}\text { Cardiovascular system } \\
\text { (heart and blood vessels) }\end{array}$ & $\begin{array}{l}\text { aerobic, anaerobic, heart rate (resting, maximum), } \\
\text { pulse, blood pressure, warm-up, cool-down }\end{array}$ \\
\hline $\begin{array}{l}\text { Respiratory system } \\
\text { (lungs) }\end{array}$ & $\begin{array}{l}\text { ventilation, heavy breathing, second wind, } \\
\text { mild/moderate/intense shortness of breath, side stitch }\end{array}$ \\
\hline $\begin{array}{l}\text { Musculoskeletal system } \\
\text { (muscle, ligament, tendon, } \\
\text { bone) }\end{array}$ & $\begin{array}{l}\text { muscle, ligament, tendon, bone, } \\
\text { isotonic/isometric/eccentric exercise, warm-up, } \\
\text { muscle fatigue, lactic acid, maximal strength, } \\
\text { muscular endurance, muscular power, muscle fatigue, } \\
\text { lactic acid, flexibility, stretching, delayed onset muscle } \\
\text { soreness (DOMS), acute muscle soreness, sprain, } \\
\text { strain, tendinitis, overtraining syndrome (OTS) }\end{array}$ \\
\hline Skin & sunburn, blister \\
\hline Thermoregulation system & $\begin{array}{l}\text { sweating, wind factor, water loss, electrolytes, } \\
\text { hyperthermia, muscle cramps, heat exhaustion, } \\
\text { heatstroke, dehydration, hypothermia }\end{array}$ \\
\hline Energy intake/expenditure & $\begin{array}{c}\text { proteins, lipids (fat), carbohydrates, calories, oxygen } \\
\text { intake, MET value }\end{array}$ \\
\hline Environment factors & $\begin{array}{l}\text { clothing, footgear, allergies (insects, plants), frostbite, } \\
\text { wind chill factor, air temperature, humidity index, } \\
\text { water temperature, water pressure, bends, altitude, } \\
\text { acute mountain sickness, hypoxia }\end{array}$ \\
\hline
\end{tabular}

Verbalization facilitates reflection, observation and understanding by providing a database in view of exchanging with others. One must however differentiate the individual's construction of exercise-management knowledge and his/her acquisition of related language. For instance, when reading about or discussing about the measurement of one's heart rate, one should be familiar with and understand the meaning of the words heart, rate, pulse (or systolic waveform), artery, wrist or neck. Most older students and adults are familiar with these terms as part of the declarative knowledge cumulated over the years. Other terms or expressions such as temperature regulation, electrolytes, FITT formula, and so on, may represent new knowledge acquired through schooling or personal reading. Nowadays, this kind of knowledge may be accessed in textbooks intended for PE fitness classes (e.g., Corbin et al. 2014, Corbin et al. 2018).

As important as it may be, PL language is but a tool that makes it possible to understand the impact of physical activity and its management. Table 2 lists a series of exercise-monitoring procedures (E-MP) that may prove useful when planning or monitoring one's PAP; such procedures, equivalent to algorithms, should be considered as procedural knowledge. E-MPs related to heart rate can be found for instance in Corbin et al. (2014), Corbin et al. (2018), or similar publications. A simple procedure for computing one's PA volume has been discussed by Godbout and Nadeau (2021). For its part, estimating one's maximum muscular strength is possible by finding which weight an individual can lift (move) at least 5 times and no more than 10 times. For instance, if a person can lift 
a $25 \mathrm{~kg}$ weight 10 times and no more, the maximal strength of that person for the muscles concerned is estimated to be 33kg (Brzycki 1993, p. 89, Corbin et al. 2014, p. 211). Working with PE teacher-students of both genders, Godbout (1975) found that despite different maximal strength levels, men and women were able to perform similar numbers of repetitions at various percentages of their strength.

Table 2. Exercise-Monitoring Procedures (E-MPs)

- Determining one's heart rate (at rest, during exercise) (see Author's note 2)

- Computing one's percentage of Maximal heart rate

- Computing one's percentage of heart rate reserve

- Computing one's PA volume

- Estimating one's maximum muscular strength

- Estimating one's level of breathing

- Estimating one's level of sweating

Although they are not quantitative monitoring procedures, estimating the level of one's breathing and one's sweating may provide the performer with some information as to the extent of his/her bodily acute reactions to exercise with regard to exercise intensity (CSEP 2011) or environmental influential conditions. Targeted aerobic conditions of exercise will yield a steady-state pulmonary ventilation associated with medium or heavy (though controlled) breathing while anaerobic conditions will bring about an out-of-breath reaction and rapid cessation of exercise, a clear indication of a too intense level of activity unless the overload was intentional, like in cases of high-intensity interval training (HIIT) or high-intensity functional training (HIFT) (see Feito et al. 2018 for a distinction between these two forms of high-intensity exercising).

Another possible indicator of exercise intensity level sometimes mentioned is the level of perspiration. While not directly related to the intensity of the PA performed, it is associated with one's thermoregulation requirements, a bodily reaction associated with exercise, room or outdoor temperature, and humidity level, notwithstanding one individual's specific conditions associated with excessive sweating or lack of it. To the author's knowledge, there is no particular sweating or perspiration scale available in the literature; nonetheless, staying aware of one's level of perspiration during exercise remains an important subjective E-MP considering possible ill-effects such as dehydration and cramps (see Table 3).

Discussing tactical knowledge in team sports, Gréhaigne and Godbout (1995) and Godbout and Gréhaigne (2021) made a distinction between action rules and play organization rules, the former focusing more on game play per se while the latter delt with the way game play was managed. Analogically, one may think of E-MPs as action rules while organization rules would translate into exercisemanagement rules (E-MR). Table 3 presents typical topics for E-MRs. These managing rules should truly be looked at as conditional knowledge, pertaining to the "if ... then" category of knowledge. Discussing the specifics of each E-MR would be beyond the scope of this article; interested readers, teachers, students and/or adults may consult guidelines such as the ones released by the Canadian 
Society for Exercise Physiology (CSEP 2011, Tremblay et al. 2011) and by the U.S. Department of Health and Human Services (2018). Of particular interest in these publications is the fact that several categories of people are considered, a recognition of the importance of regulating exercise-management based on individuals' various needs at different periods of their life. Information provided by textbooks on fitness development and control (e.g., Corbin et al. 2014, 2018) may be of interest as well. Accessing this level of knowledge implies understanding and critical thinking on the part of a PA-literate individual as we will discuss in the next section of the article. Readers will note that several of the topics included in Table 2 and 3 may be associated with the "control competence" or the "self-regulation competence" identified in the Physical Activity-related Health Competence model (Carl et al. 2020, Sudeck and Pfeifer 2016).

Table 3. Typical Topics for Exercise-Management Rules (E-MRs)

- Managing the FITT formula

- $\quad$ Managing APR pattern (Activation, Performing stage ${ }^{1}$, Recovery)

- Managing safety measures (clothing and footgear, weather [heat/cold/humidity], food/liquids, sun conditions, outdoor allergies, proper equipment, overloading risks ${ }^{2}$ )

- Managing outdoor environment (footgear and terrain, clothing and weather)

- Managing weather conditions: temperature, humidity, hydration, sunburns

- Managing reversibility ${ }^{3}$ and getting back to exercising

- Managing muscle cramps or side stitches

- Managing diminishing return ${ }^{3}$

- Managing exercise overload ${ }^{3}$ and signs of overtraining syndrome

${ }^{1}$ Made of continuous, short-interval and/or long-interval exercise.

${ }^{2}$ See Author's note 3 .

${ }^{3}$ See Gannon (2004, section 2).

\section{Understanding and Intelligence with Regard to Health- and Fitness-Oriented Physical Activities}

From a constructivist perspective, becoming self-directing and self-actualizing with regard to one's PAP (Klesius 1971) implies understanding and thinking on the part of this individual, two characteristics related to intelligence (Godbout and Gréhaigne 2021). The building-knowledge process, as opposed to the acknowledging process, is paramount in light of understanding. Related mental processes should eventually lead to the development of PL intelligence.

\section{Understanding the Mechanics of Regular Physical Activity Practice}

Beyond a first level of understanding related to language assimilation, students' or adults' challenge remains to understand the notions of E-MRs and EMPs listed in Tables 2 and 3 and to make them their own either through assimilation or through accommodation (see Godbout and Gréhaigne 2021, pp. $48-49$, for a summary of the knowledge-construction process though assimilation, 
accommodation and adaptation). While assimilating includes storing knowledge, either declarative or procedural, into one's memory, accommodation means adjusting the theory of acute and/or chronic effects to one's reality through (a) reflection on the effects experienced, (b) hypotheses about possible consequences of new patterns of activity or particular adjustments to familiar ones, and (c) verification of and reflection on obtained results. An additional level of understanding is displayed when the individual can apply the management of one activity to another one and obtain similar results. In such cases, we will consider that the individual has adapted. As is the case with PL language discussed earlier, understanding E-MRs goes beyond a simple cognitive process. Through accommodation and adaptation, PA literates make such rules their own, embodying knowing and understanding.

While understanding physical activity has often been discussed with regard to tactical learning in team sports (e.g., Godbout and Gréhaigne 2021, Nadeau et al. 2020, Ramos et al. 2020, Zerai et al. 2020), it is quite possible to analogically associate PA-management decision-making to the use of tactics and strategy. Planning long-term PA projects (over one season or one year, for instance) calls for strategic choices: registering into a fitness program; buying particular pieces of equipment, clothing and/or footgear; etc. As time goes by, particular constraints may arise, calling for adjustments that require tactical thinking. When applying management rules, individuals will use convergent thinking (Godbout and Gréhaigne 2021) if they are familiar with the principles and decisions involved; through analyzing, evaluating, judging, comparing and contrasting, convergent thinking focuses on problem solving based on known procedures. Should individuals encounter an unfamiliar problem or look for different solutions to a familiar problem, they will likely resort to divergent thinking to imagine, create, invent solutions and verify their appropriateness (Godbout and Gréhaigne 2021). For instance, one may think that choosing to go jogging with a baby or an infant in a stroller, to go cycling while pulling a bicycle trailer, or to go running tied to one's dog are examples of solutions originally found through divergent thinking. Putting a T-shirt on to go snorkeling on a sunny day is another example of divergent thinking related to one's safety. Walking down a mountain slope in zigzag to avoid an excessive amount of eccentric contractions in the thighs and consecutive DOMS the day after is again another example of divergent tactical thinking; and on, and on. Necessity is the mother of inventions; that often goes for exercise management, provided that safety measures are taken. The individuals' capacity for planning and adjusting their PAP, whatever circumstances arise, rests on their PL intelligence.

\section{Developing PL Intelligence in Terms of Exercise Management}

Theorizing about intelligence is not the purpose of this article. It seems nevertheless useful to provide readers with a few basic considerations followed by a discussion on the development of PL intelligence as it relates to exercise management. 
Theoretical Considerations

Discussing game-play intelligence, Godbout and Gréhaigne (2021) resorted to an operational definition offered by the French Centre national de ressources textuelles et lexicales (2020). They wrote (Godbout and Gréhaigne 2021, p. 9):

in new circumstances for which instinct, learning or habit has no solution, [intelligence is] the aptitude for (a) grasping (comprehending) and organizing situational data, (b) putting together procedures to be used and the final aim, (c) choosing appropriate means or (d) discovering original solutions that will allow an adaptation to the requirements of the action. ... Followed by a complement referring to an activity [PAP management, for example], the word intelligence is defined as an aptitude, a particular capacity, a gift for the activity concerned.

Thus, one may consider intelligence as an aptitude or a particular capacity whose development depends on the amount of knowledge, concepts and conceptual networks cumulated and understood by a person.

In this article, the author will consider PL intelligence, in terms of exercise management, as an individual's capacity to use both strategic and tactical thinking to manage his/her PAP given acute and chronic effects pursued.

\section{$\underline{\text { PL Intelligence in Terms of Exercise Management }}$}

Based on Sternberg's $(1985,2005)$ theory of intelligence, the author will use the notions of analytical, creative and practical intelligence. Analytical intelligence is at work when a person analyzes, evaluates, judges, or compares and contrasts. It may therefore be associated with convergent thinking which focuses on problem solving based on known procedures. For its part, creative intelligence enables individuals to invent or imagine one or different solutions to a new problem; it manifests itself through divergent thinking as defined above. Finally, through practical intelligence, individuals apply their abilities to the kinds of problems that confront them in daily life. Practical intelligent people adapt, shape or select environments. "Adaptation is involved when one changes oneself to suit the environment. Shaping is involved when one changes the environment to suit oneself. And selection is involved when one decides to seek out another environment that is a better match to one's needs, abilities, and desires" (Sternberg 2005, p. 193). One may consider that convergent or divergent thinking is involved depending upon which particular situation arises.

Applying E-MRs listed in Table 3 implies, on the part of the PA literate, the learning of a vast amount of knowledge, be it declarative, procedural or conditional. Beyond the understanding of concepts and multiple constructs, individuals must develop conceptual networks involving combinations of specific pieces of procedural knowledge. The management of the FITT formula is particularly representative of PL intelligence at work, calling for joint and simultaneous decisions about the intensity, duration, frequency and type of exercise, all this taking into account the weather conditions and the particular physical environment in which the exercise will take place. Some of the E-MRs to be applied may rely on practical intelligence (selecting proper gear for a given environment or selecting a proper environment given the gear at one's disposal for 
instance). Other E-MRs are more complex and require either analytical or creative intelligence.

Two of these E-MRs offer a regular and systematic challenge to the performer: (a) managing the FITT formula; (b) managing APR pattern (activation, performing stage, recovery). In a sense, these two rules may be seen as advanced organizers either for the learner or the adult PA literate. On the one hand, as mentioned earlier, the application of the FITT formula always calls for decisions regarding frequency $(\mathrm{F})$, intensity $(\mathrm{I})$, time $(\mathrm{T})$, and type of activity $(\mathrm{T})$ (readers may consult Godbout and Nadeau 2021 for a more elaborate discussion on that topic). On the other hand, the APR pattern may also be considered an advance organizer in the sense that, whatever the bout of exercise and despite possible variations of stimulus-intensity, a person will always depart from a resting state, experience an increased activity of various body systems until cessation of exercise, and go through recovery until resting state is restored. Within the parameters of each of these advance organizers, the performer will use one type of intelligence or another (mostly analytical or creative) to make decisions and come up with plans of actions. For instance, a person may choose, through creative intelligence and divergent thinking, to experience all kinds of variation of intensities during the performance stage of the APR pattern, using continuous, short-interval, long-interval phases or some combination of them. At times, natural features of the physical environments may provide such varied conditions. Although not so systematic in its application, the managing-safety-measures rule plays the role of advance organizer as well. This particular E-MR covers several "if ... then" propositions associated with varied aspects of PA such as thermoregulation (e.g., if hot weather, drink more; if heavy sweating, restore body electrolytes to avoid cramps), clothing and footgear (e.g., if the exercise may cause hand blisters, wear protection gloves; if jogging elicit foot problems or shin splints, look for proper running shoes; if cold weather, wear layers of clothes with synthetic inner layer to let the sweat pass through the fabric), etc.

Incorporating E-MRs into one's regular PAP implies an awareness and some level of regulation of one's exercise-management knowledge and understanding.

\section{Exercise-Management Knowledge and Understanding: Awareness and Regulation}

Godbout and Nadeau (2021, p. 13) stated that "awareness of one's knowledge and understanding means that the individual knows to what extent he/she understands the principles of regular PA regarding the FITT formula, the acute and chronic effects of exercise, etc." Awareness of one's exercise management goes a step further in the sense that the PA literate should take notice of the way he or she applies the various E-MPs and E-MRs presented in Table 2 and Table 3. Failure to apply these procedures or these rules properly may be indicative of a lack of related knowledge, a lack of understanding, and/or the need for further conceptual development. As individuals become more self-directing and self-actualizing (Klesius 1971), self-regulation of exercise management ought to set in. Through the development process of autonomy, co-regulation scenarios may well play an 
important role (see Godbout and Nadeau 2021, for an elaborate discussion of coregulation and socially shared regulation associated with PAP regulation).

Whatever particular type of regulation is concerned, some form of monitoring is required (Godbout and Gréhaigne 2020). Besides using formal monitoring procedures evoked in Table 2, individuals may also take advantage of natural clues provided by their body throughout the APR pattern alluded to earlier. Any activation/performing/recovery triad produces various acute effects. Three bodily adjustments easily noticeable are (a) variations in the heart rate, (b) variations in breathing, and (c) appearance of sweat. Noticing a significant increase in breathing and medium to heavy sweating (Tidén et al. 2021) is simply a matter of common sense. For its part, heart rate may be easily monitored by hand (see Corbin et al. 2014, pp. 166-167, for instance) or can be determined with the help of wearable electronic devices. Should the cardiovascular, respiratory or thermoregulation system fail to increase noticeably, there is cause for adjustment of the FITT formula.

Contrary to the management of the APR pattern and of the FITT formula, other aspects of PAP management do not necessarily call for systematic regulation, although preventive monitoring remains advisable. This is the case for management rules pertaining to safety since acute effects may have negative consequences (e.g., dehydration, sunburns, blisters); some chronic effects may also lead to injuries (a most frequent one being the tendinitis). Should an individual tend to suffer from exercise-related ill-effects on a regular basis, this would mean that the person is not managing properly his/her PAP and needs to develop further knowledge and understanding. Finally, other aspects of management regulation may be called for, depending upon particular constraints that occur in one's everyday life, or upon life changes freely implemented by people.

\section{Limitations}

As briefly mentioned in the introduction, knowledge and understanding discussed in this article do not relate to the specifics of every physical activity that can be considered by individuals when planning their PA practice. Each category of activity, if not each activity in itself, may be studied, discussed and learned based on a specific content knowledge and its related logic, understanding and language. Not even a single book could consider so much information. Knowledge and understanding considered above is limited to the management, or regulation, of one's PAP, whatever the particular activity might be, considering the acute and chronic effects of exercise on the human body. It is likely that one's PAP bears also consequences psychologically and socially; these dimensions of the impact of PAP have not been examined, not only for lack of space but for lack of knowledge as well on the part of the author. 


\section{Conclusion}

This article has discussed PL PCK, language, and intelligence as they relate to exercise management. Three other PL components were not specifically taken into consideration; they are physical competence, motivation and confidence, and lifetime engagement. Motivation and lifetime engagement have been discussed in line with a constructivist approach (Godbout and Nadeau 2021) and the author elected not to consider physical competence related to specific physical activity, given the bulk of PCK content involved and the fact that the article targets older students and adults who have likely developed a significant base of physical competence throughout the years and/or can still choose to develop new PA competences on their own within the community. Intelligent management of PAP calls for people to use knowingly E-MPs and E-MRs conducive to sound selfand/or co-regulation. In the perspective of preparing older students for an autonomous and self-regulated lifetime PA engagement, PE teachers ought to target their students' development of PAP-management related language and intelligence.

Author's note 1. In this article, "sport education" does not refer to Siedentop's $(1994,1998)$ instructional model. It refers to children's, adolescents' and older students' educational experiences in out-of-PE- lessons sport programs offered them under the form of intramural and interschool competition, community-led sport leagues programs, specialized summer camps, etc. Through coaching, PE-trained educators and other sport educators contribute largely to the participants' sport education.

Author's note 2. Despite the fact that smart mobile devices such as smartwatches make it easier for performers to monitor their heart rate, older students and active adults should still understand the mechanics of the procedure as a way to embody their knowledge concerning acutes effects of exercise.

Author's note 3. There has been in recent years an increased interest for high-intensity interval training (HIIT) and high-intensity functional training (HIFT) exercises (Feito et al. 2018). Such exercises should be performed with proper preparation due to higher risks of musculoskeletal injuries (Rynecki et al. 2019).

\section{References}

Amade-Escot C (2000) The contribution of two research programs on teaching content: "pedagogical content knowledge" and "didactics of physical education". Journal of Teaching Physical Education 20(1): 78-101.

Bonnie RJ, Stroud C, Breiner H (Eds.) (2015) Investing in the health and well-being of young adults. Washington, D.C.: The National Academic Press.

Brzycki M (1993) Strength testing - Predicting a one-rep max from reps-to-fatigue. Journal of Physical Education, Recreation \& Dance 64(1): 88-90.

Canadian Society for Exercise Physiology - CSEP (2011) Handbook for Canada's physical activity guide. Ottawa, Canada: Public Health Agency of Canada. 
Cale L, Harris J (2018) The role of knowledge and understanding in fostering physical literacy. Journal of Teaching in Physical Education 37(3): 280-287.

Carl J, Sudeck G, Pfeifer K (2020) Competencies for a healthy physically active lifestyle - Reflections on the model of physical activity-related health competence. Journal of Physical Activity and Health 17(7): 688-697.

Centre national de ressources textuelles et lexicales - CNTRL (2020) Lexicographie, intelligence (Lexicography, intelligence). Retrieved from: https://www.cnrtl.fr/ definition/Intelligence/substantif. [Accessed 10 June 2021]

Corbin CB, Le Masurier GC, McConnel KE (2014). Fitness for life. $6^{\text {th }}$ Edition. Champaign, IL: Human Kinetics.

Corbin CB, Welk G, Corbin W, Welk K (2018) Concepts of fitness and wellness: a comprehensive lifestyle approach. 12th Edition. New York (NY): McGraw-Hill Education.

Edwards LC, Bryan AS, Keegan RJ, Morgan K, Jones AM (2017) Definitions, foundations and associations of physical literacy: a systematic review. Sports Medicine 47(1): 113-126.

Escalié G, Recoules N, Chaliès S, Legrain P (2019) Helping students build competences in physical education: theoretical proposals and illustrations. Sport, Education and Society 24(4): 390-403.

Feito Y., Heinrich KM, Butcher SJ, Carlos Poston WS (2018) High-intensity functional training (HIFT): definition and research implications for improved fitness. Sports 6(3): 76.

Gannon GA (2004) Guidelines for fitness assessment in Manitoba schools: a resource for physical education/health education. Revised Edition. Winnipeg (Manitoba): Manitoba Education, Citizenship and Youth.

Godbout P (1975, September) A study on the relationship between muscular strength and muscular endurance. Paper presented at the Meeting of the Canadian Association for Sport Sciences. Ottawa, Canada.

Godbout P, Gréhaigne J-F (2020) Regulation of tactical learning in team sports - The case of the tactical-decision learning model. Physical Education and Sport Pedagogy (Advance Online Publication, December 22).

Godbout P, Gréhaigne J-F (2021) Game-play language and game-play intelligence Wording, planning, and enacting action plans in team sports. Athens Journal of Sports 8(1): 47-64.

Godbout P, Nadeau L (2021) A physical activity practice index for older students and adults. Athens Journal of Sports 8(2): 99-120.

Gréhaigne J-F, Godbout P (1995) Tactical knowledge in team sports from a constructivist and cognitivist perspective. Quest 47(4): 490-505.

Klesius SE (1971) Physical Education in the seventies: where do you stand? Journal of Health, Physical Education, \& Recreation 42(2): 46-49.

Klieme E, Hartig J, Rauch D (2008) The concept of competence in educational contexts. In J Hartig, K Klieme, D Leutner (eds.), Assessment of Competencies in Educational Contexts, 3-22. Gottingen, Germany: Hogrefe \& Huber Publishers.

Konukman F, Henschel Pellett H, Pellett TL (2010) Building physical education knowledge and understanding through vocabulary activities. Journal of Physical Education, Recreation \& Dance 81(6): 49-52.

Lumen learning team (2019) Lifespan development - Physical development in early adulthood. Retrieved from: https://courses.lumenlearning.com/wmopen-lifespandeve lopment/chapter/physical-development-in-early-adulthood/. [Accessed 10 June 2021] 
Nadeau L, Martel D, Poulin-Beaulieu I, Couture-Légaré J (2020) L'utilisation de la technique des incidents critiques pour favoriser la réflexion de joueurs en sports collectifs (The use of critical incidents to enhance players' reflection on action in team sports). eJournal de la Recherche sur l'Intervention en Éducation Physique et Sport Spécial (3): 93-113.

Ramos A, Coutinho P, Davids K, Mesquita I (2020) Developing players' tactical knowledge using combined constraints-led and step-game approaches - A longitudinal action-research study. Research Quarterly for Exercise and Sport (Epub Ahead of Print, July 9).

Ryan RM, Deci EL (2020) Intrinsic and extrinsic motivation from a self-determination theory perspective: definitions, theory, practices, and future directions. Contemporary Educational Psychology 61(Apr): 101860.

Rynecki ND, Siracuse BL, Ippolito JA, Beebe KS (2019) Injuries sustained during high intensity interval training: are modern fitness trends contributing to increased injury rates? The Journal of Sports Medicine and Physical Fitness 59(7): 1206-1212.

Schunk DH (2012) Learning theories - An educational perspective. Boston (MS): Pearson Education, Inc.

Siedentop D (1994) Sport education: quality PE through positive sport experiences. Champaign, IL: Human Kinetics.

Siedentop D (1998) What is Sport Education and how does it work? Journal of Physical Education, Recreation \& Dance 69(4): 18-20.

Sternberg RJ (1985) Beyond IQ: a triarchic theory of human intelligence. Cambridge: Cambridge University Press.

Sternberg RJ (2005) The theory of successful intelligence. Revista Interamericana de Psicologí/Interamerican Journal of Psychology 39(2): 189-202.

Sudeck G, Pfeifer K (2016) Physical activity-related health competence as an integrative objective in exercise therapy and health sports - Conception and validation of a short questionnaire. Sportwissenschaft 46(2): 74-87.

Tidén A, Brun Sundblad G, Lundvall S (2021) Assessed movement competence through the lens of Bourdieu - A longitudinal study of a developed taste for sport, PE and physical activity. Physical Education and Sport Pedagogy 26(3): 255-267.

Tremblay MS, Warburton DER, Janssen I, Paterson DH, Latimer, AE, Rhodes RE, et al. (2011) New Canadian physical activity guidelines. Applied Physiology, Nutrition, and Metabolism 36(1): 36-46.

U.S. Department of Health and Human Services (2018) Physical activity guidelines for Americans. $2^{\text {nd }}$ Edition. Washington, D.C.: U.S. Department of Health and Human Services.

Weiss MR (2011) Teach the children well: a holistic approach to developing psychosocial and behavioral competencies through physical education. Quest 63(1): 55-65.

Wesselink R, Dekker-Groen AM, Biemans H, Mulder M (2010) Using an instrument to analyze competence-based study programmes: experiences of teachers in Dutch vocational education and training. Journal of Curriculum Studies 42(6): 813-829.

Whitehead M (2013) Definition of physical literacy and clarification of related issues. Journal of Sport Science and Physical Education 65(Oct): 29-34.

Wickens CM, Parker J (2019) Supporting vocabulary acquisition in physical education settings. Journal of Physical Education, Recreation \& Dance 90(5): 16-22.

Zerai Z, Gréhaigne J-F, Godbout P (2020) Student understanding and learning in team sports: understanding through game-play analysis. Athens Journal of Sports 7(4): 215-234. 
Zhang T, Deng A, Chen A (2020) The missing link? Middle school students' procedural knowledge on fitness. Journal of Teaching in Physical Education 40(3): 474-483. 